\title{
Satiating Effects of Cocaine Are Controlled by Dopamine Actions in the Nucleus Accumbens Core
}

\author{
Nobuyoshi Suto ${ }^{1,2}$ and Roy A. Wise ${ }^{1}$ \\ ${ }^{1}$ Behavioral Neuroscience Branch, Intramural Research Program, National Institute on Drug Abuse, NIH/DHHS, Baltimore, Maryland 21224, and \\ ${ }^{2}$ Maryland Psychiatric Research Center, Department of Psychiatry, University of Maryland Baltimore School of Medicine, Baltimore, Maryland 21228
}

Intravenous cocaine intake in laboratory animals is characterized by periods of apparent drug satiety between regularly spaced earned injections. The reinforcing properties of cocaine are linked primarily to dopaminergic neurotransmission in the shell and not the core of nucleus accumbens. To determine whether the satiating effects of cocaine are similarly mediated, we perfused dopamine receptor agonists into the core or the shell during intravenous cocaine self-administrations by rats. Neither D1-type (SKF38393) nor D2-type (quinpirole) agonist was effective when given alone. However, a combination of the two agonists perfused into the core but not the shell significantly increased the time between cocaine self-injections, decreasing the amount of earned intake. Together with previous findings, the current data suggest that the satiating and reinforcing effects of cocaine are mediated by different ventral striatal output neurons.

\section{Introduction}

Experienced laboratory rats self-administer intravenous psychomotor stimulants at regular intervals, maintaining relatively constant rates of drug intake despite major variations in unit dose or response requirement (Pickens and Thompson, 1968; Yokel and Pickens, 1974). Although they self-administer these drugs to the point of death when given unlimited access, death under these circumstances follows severe loss of weight and is rarely, if ever, a consequence of drug overdose (Johanson et al., 1976; Bozarth and Wise, 1985). While the mechanism for response spacing is not known, it is learned over the first few weeks of training and is thought to reflect periods of drug satiety (Dougherty and Pickens, 1974; Gerber and Wise, 1989; Wise et al., 1995) analogous to the satiety periods between meals. Indeed, the pacing of stimulant self-administration is well modeled by assuming that drug craving during a session returns when the drug level from previous injections is metabolized below a "satiety threshold" (Tsibulsky and Norman, 1999).

It is the postsynaptic consequences of drug-induced elevations of extracellular dopamine that are responsible for the rewarding effects of cocaine (De Wit and Wise, 1977; Risner and Jones, 1980) and amphetamine (Yokel and Wise, 1975, 1976; Risner and Jones, 1976). In the case of cocaine, this results from the blockade of dopamine uptake (Heikkila et al., 1975), primarily, but perhaps not exclusively (Carboni et al., 1990; Morón et al.,

\footnotetext{
Received April 15, 2011; revised 0ct. 18, 2011; accepted 0ct. 19, 2011

Author contributions: N.S. and R.A.W. designed research; N.S. performed research; N.S. analyzed data; N.S. and R.A.W. wrote the paper.

This work was supported by funding from the Intramural Research Program, National Institute on Drug Abuse, National Institutes of Health, Department of Health and Human Services, as well as NIDA Residual Research Services (N01DA-5-9909). We thank Dr. Greg Elmer for the help on the statistical analyses.

Correspondence should be addressed to Nobuyoshi Suto at his present address: Molecular and Integrative Neurosciences Department (M.I.N.D.), The Scripps Research Institute, 10550 North Torrey Pines Road, La Jolla, CA 92037 , Maildrop:SP30-2120. E-mail: nsuto@scripps.edu.

DOI:10.1523/JNEUROSCI.1903-11.2011

Copyright $\odot 2011$ the authors $\quad 0270-6474 / 11 / 3117917-06 \$ 15.00 / 0$
}

2002), by the dopamine transporter (Thomsen et al., 2009). Partial blockade of dopamine receptors causes shorter pauses in stimulant self-administration; more severe blockade causes response cessation (Yokel and Wise, 1975, 1976; Risner and Jones, 1976; De Wit and Wise, 1977; Ettenberg et al., 1982). Lesion studies implicate dopamine actions in the nucleus accumbens (NAS) (Roberts et al., 1977; Lyness et al., 1979).

NAS comprises two subregions: the "core" (contiguous with the overlying caudate-putamen), and the "shell" (contiguous with the underlying olfactory tubercle) (Voorn et al., 1989; Zahm and Heimer, 1990; Berendse et al., 1992). Extracellular dopamine in both core and shell is elevated during intravenous cocaine self-administration (Lecca et al., 2007; Suto et al., 2010). Whereas NAS core does not appear to be important for the reinforcing effects of cocaine as reflected in response acquisition (Carlezon and Wise, 1996a; Ikemoto, 2003; Ito et al., 2004), we have recently found that local blockade of dopamine receptors in NAS core but not the shell shortens the inter-response intervals in well trained animals (Suto et al., 2009). This effect is reminiscent of the compensatory increase in intravenous cocaine intake induced by lowering the drug dose or by systemic application of dopamine antagonists (Yokel and Wise, 1975, 1976; De Wit and Wise, 1977), and appears to reflect shortened periods of cocaine satiety (Gerber and Wise, 1989; Norman and Tsibulsky, 2001). Thus, the mechanism for cocaine satiety may be distinct from that of cocaine reinforcement. To explore this possibility more fully, we have assessed the effects of local perfusion of dopamine receptor agonists in NAS core or shell during ongoing intravenous cocaine self-administration.

\section{Materials and Methods}

All procedures were approved by the local Animal Care and Use Committee. Fifty-one male Long-Evans rats (Charles River), weighing 350$400 \mathrm{~g}$ at the time of surgery, were used. The experiment comprised two phases: cocaine self-administration training (10 d) and testing $(3 \mathrm{~d})$. The rats were randomly assigned to one of six experimental groups defined by the 
site of agonist perfusion (core or shell) and the type of agonists. Three agonist treatments were given: 2,3,4,5-tetrahydro-7,8-dihydroxy-1phenyl-1 H-3-benzazepine [SKF38393 (SKF; D1type agonist)], quinpirole (QUIN; D2-type agonist), and an equimolar mixture of SKF38393 and quinpirole (SKF + QUIN) (Sigma).

Each rat was implanted with an intravenous catheter (Braintree Science) and bilateral guide cannulae (CMA Microdialysis) aimed at either NAS core or shell as previously described (Suto et al., 2009, 2010). The cannulae were positioned at $1.0 \mathrm{~mm}$ above the tip of probes. The intravenous catheters were flushed daily with $0.05 \mathrm{ml}$ of heparin solution $(30 \mathrm{U} / \mathrm{ml}$ in sterile saline). One rat did not complete the experiment because of a leaking catheter.

Following recovery ( $3 \mathrm{~d}$ ), each rat was housed in an operant conditioning chamber (Med Associates). Each operant chamber was equipped with two levers (one removable "active lever" and one stationary "inactive lever"), a house light, a cue light, and a liquid swivel system. Food and water were available ad libitum.

Cocaine self-administration training began $3 \mathrm{~d}$ after the surgery and continued daily for $10 \mathrm{~d}$. Cocaine ([-]-cocaine hydrochloride) was obtained from the NIDA pharmacy and was dissolved in sterile saline $(0.9 \%, \mathrm{w} / \mathrm{v})$. At the beginning of each session, the active levers were inserted into the operant chambers and each rat received a priming injection of cocaine $(1.0 \mathrm{mg} / \mathrm{kg}$, i.v.). They were then allowed to self-administer cocaine $(1.0 \mathrm{mg} / \mathrm{kg}$ per infusion, i.v.) under a fixed ratio 1 (FR1) schedule of reinforcement for $4 \mathrm{~h}$. A press on the active lever delivered a cocaine injection $(0.13 \mathrm{ml})$. During a $20 \mathrm{~s}$ "time-out" period immediately following a reinforced lever press, the cue light was illuminated and presses on the active lever were ineffective. Presses on the inactive lever were without scheduled consequence. The training criterion was two consecutive days of stable responding $(<10 \%$ day-to-day variability) with a minimum of 25 injections per session. Two rats failed to achieve this criterion and were excluded. Upon completion of the last training session, microdialysis probes with $1.0 \mathrm{~mm}$ active membrane (CMA Microdialysis, CMA/12-14/01) were bilaterally inserted into core or shell. The probes were continuously perfused with artificial CSF (aCSF; composition in mM: $148 \mathrm{NaCl}, 2.7 \mathrm{KCl}, 1.2 \mathrm{CaCl}_{2}, 0.8 \mathrm{MgCl}_{2}, \mathrm{pH}$ $7.4)$ at the rate of $2.0 \mu \mathrm{l} / \mathrm{min}$.

On the next $3 \mathrm{~d}$, the rats underwent cocaine self-administration testing. During each testing session, rats were allowed to self-administer cocaine $(1.0 \mathrm{mg} / \mathrm{kg} /$ injection, i.v.) under FR 1 for $4 \mathrm{~h}$. Each testing session was divided into "loading" (the first hour) and "maintenance" (next $3 \mathrm{~h}$ ) phases. During the loading phase, the rats received no agonist. During the maintenance phase, each rat received SKF, QUIN, or SKF + QUIN perfused through the dialysis probes (reverse dialysis) at the rate of 2.0 $\mu \mathrm{l} / \mathrm{min}$. Each agonist and the equimolar mixture were dissolved in aCSF and adjusted to $\mathrm{pH} 7.4$ before use. Three doses of each agonist $(0.0,0.1$, $1.0 \mathrm{~mm}$ for SKF or QUIN; 0.0, $0.05+0.05,0.5+0.5 \mathrm{~mm}$ for SKF + QUIN) were tested in each animal in a counterbalanced design, one dose per day in random sequence. Responses and injections were recorded.

Perfusion of SKF + QUIN into core significantly altered cocaine selfadministration. The effects of this manipulation on different unit doses of self-administered cocaine were characterized in an additional dose- response study. For this, eight animals were surgically implanted with an intravenous catheter and guide cannulae into the core, underwent cocaine self-administration training, and received microdialysis probes as described above. Following this training, the rats underwent dose-response testing for $3 \mathrm{~d}$. Each dose-response session lasted for $7 \mathrm{~h}$, and was divided into the loading (first hour) and maintenance (next $6 \mathrm{~h}$ ) phases. During the loading phase, the rats were allowed to self-administer the training dose of cocaine $(1.0 \mathrm{mg} / \mathrm{kg}$ per infusion) and received no agonist. During the maintenance phase, the rats received core-SKF + QUIN perfusion $(0.0,0.05+0.05$ or 0.5 $+0.5 \mathrm{~mm}$ ). Cocaine self-administration during the maintenance phase was subdivided into three $2 \mathrm{~h}$ blocks. During the first block, the rats continued to self-administer the training dose of cocaine. During the second and third blocks, the unit doses of cocaine were lowered to 0.5 and $0.25 \mathrm{mg} / \mathrm{kg}$ per infusion, respectively. Responses and injections were recorded.

After completion, the rats were anesthetized with sodium pentobarbital, the brains were fixed in $10 \%$ formalin, and coronal sections $(40 \mu \mathrm{m})$ were mounted and stained with cresyl violet. Only data obtained from animals with both probes placed within the core or shell 




$\square$ aCsF

$0.1 \mathrm{mM}$ (SKF, QUIN) or $0.05+0.05 \mathrm{mM}$ (SKF+QUIN) $1.0 \mathrm{mM}$ (SKF, QUIN) or $0.5+0.5 \mathrm{mM}(\mathrm{SKF}+\mathrm{QUIN})$

Figure 2. Effects of bilateral perfusion of D1-type (SKF), D2-type (QUIN), and D1 + D2-type (SKF + QUIN) agonists into NAS core and shell on cocaine intake. Data are shown as the mean ( + SEM) total numbers of cocaine self-injections during the $3 \mathrm{~h}$ maintenance phase. ${ }^{*} p<0.05$ vs aCSF as revealed by post hoc Tukey's HSD comparisons following ANOVA. $n=6-8$ per group.
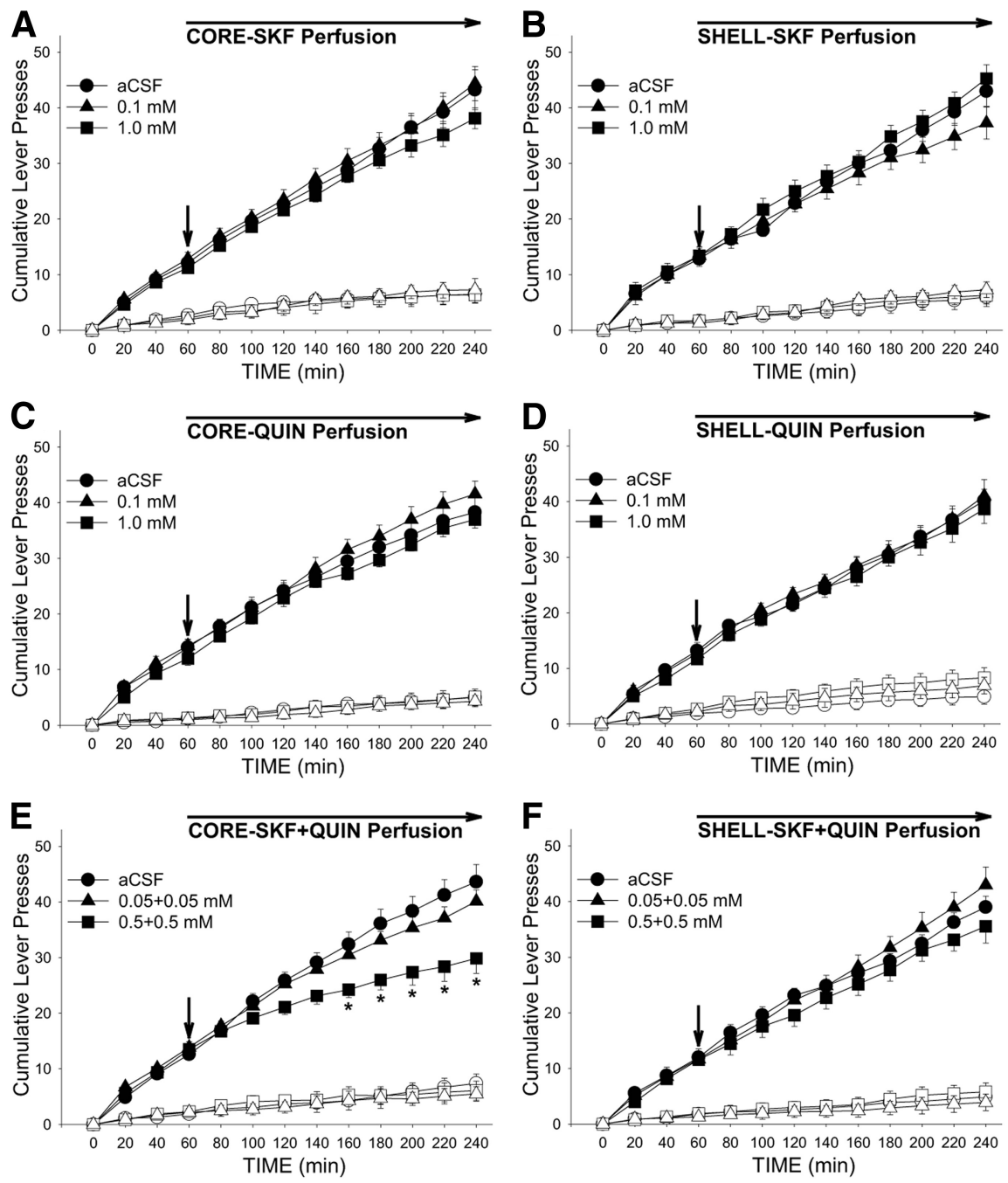

Figure 3. Effects of bilateral perfusion of D1-type (SKF), D2-type (QUIN), and D1 + D2-type (SKF + QUIN) agonists into NAS core and shell on cocaine-seeking. For $\boldsymbol{A}-\boldsymbol{F}$, solid and open symbols respectively depict the mean ( \pm SEM) numbers of active and inactive lever presses. Arrows depict the starting point of agonist perfusion. ${ }^{*} p<0.05$ vs aCSF as revealed by posthoc Tukey's HSD comparisons following ANOVA. $n=6-8$ per group. were retained for statistical analyses. Neither "cross-hemisphere" placements for shell through midline nor the placements for core result in extensive damage beyond cannulae and probes (Fig. 1; see also Suto et al., 2009, 2010). Five rats were excluded from statistical analysis because one or both probes were outside the targeted area. Final numbers of subjects were core-SKF, 8; core-QUIN, 7; core-SKF + QUIN, 8; shellSKF, 7; shell-QUIN, 6; shell-SKF + QUIN, 7; dose-response, 8.

Total numbers of cocaine self-injections during the loading ( $1 \mathrm{~h}$ total $)$ and maintenance $(3 \mathrm{~h}$ total) phases of cocaine self-administration testing were separately analyzed using two-way between-within ANOVA with Site (2 levels) and Type (3 levels) of agonist perfusion as the between factors and Dose (3 levels: vehicle, low, and high) as the within factor. Cumulative numbers per $20 \mathrm{~min}$ of active and inactive lever presses during testing were separately analyzed for each experimental group using two-way within ANOVA with Dose (3 levels) and Time (12 levels) as the within factor. Total numbers of cocaine self-injections during the loading phase ( $1 \mathrm{~h}$ totals) were analyzed using two-way ANOVA with Cocaine Dose (3 levels: 0.25, 0.5, and $1.0 \mathrm{mg} / \mathrm{kg}$ per infusion) and Agonist Dose (3 levels: vehicle, low, and high) as within-subject factors. Similarly, total numbers of cocaine self-injections and active lever presses during each of the three blocks of the maintenance phases ( $2 \mathrm{~h}$ totals) were analyzed using two-way ANOVA with Cocaine Dose (3 levels) and Agonist Dose (3 levels) as withinsubject factors. For all cases, Tukey's HSD test was used for post hoc comparisons. All analyses were conducted with Statistica (1999 edition) and JMP (version 5) software.

\section{Results}

Perfusion of a mixture of the higher concentrations of the D1- and D2-type dopamine agonists, SKF and QUIN, decreased cocaine intake (Fig. 2) and active lever pressing (Fig. 3) when injected into NAS core but not shell. The effect on cocaine intake at our standard dose of $1.0 \mathrm{mg} / \mathrm{kg} /$ injection was confirmed by a significant Site $\times$ Dose interaction $\left(F_{(2,74)}=3.44\right.$, $p<0.05)$ and Tukey's HSD post hoc comparisons $(p<0.01)$ from ANOVA conducted on the total numbers of cocaine injections obtained during the maintenance phase ( $3 \mathrm{~h}$ totals). Active lever pressing began to slow shortly after the perfusion was initiated (Fig. $3 E$ ) and was significantly lower than control (aCSF) rates for the last $100 \mathrm{~min}$ of the session as reflected in the effects of Dose $\left(F_{(2,74)}=\right.$ $3.44, p<0.05)$ and Dose $\times$ Time interaction $\left(F_{(22,231)}=4.84, p<0.001\right)$, and post hoc comparisons ( $p$ values $<0.05-0.01$ ). Perfusion of the combination of SKF and QUIN into shell was ineffective, as were perfusions of either agonist alone into either brain region (Fig. 3). 
SKF + QUIN perfusion into the NAS core were similarly effective at two additional unit doses of cocaine (Fig. 4). The effect on cocaine intake was confirmed by significant Cocaine $\left(F_{(2,6)}=29.54, p<\right.$ $0.001)$ and Agonist $\left(F_{(2,6)}=6.61, p<\right.$ $0.05)$ effects and by post hoc comparisons $(p<0.01-0.05)$ from ANOVA conducted on the total numbers of cocaine self-injections during each of three $2 \mathrm{~h}$ blocks of the maintenance phase. The effect on active lever press was confirmed by significant main effects of Cocaine Dose $\left(F_{(2,6)}=61.31, p<0.001\right)$ and Agonist Dose $\left(F_{(2,6)}=14.25, p<0.01\right)$ and by Tukey's HSD post hoc comparisons $(p<$ 0.01-0.05) from ANOVA conducted on the total numbers of active lever press during each of the three blocks of the maintenance phase ( $2 \mathrm{~h}$ totals). Under all agonist conditions (vehicle, low dose, high dose), the rats achieved significantly greater cocaine self-injections (Fig. $4 A$ ) and active lever presses (Fig. $4 B$ ) for lower unit doses of self-administered cocaine ( $p$ values $<0.001-0.05$ ).

There were no between-group differences in cocaine selfadministration before the intracranial perfusion of dopamine agonists. This was confirmed by ANOVA conducted on the total numbers of cocaine injections obtained during the agonist-free loading phase ( $1 \mathrm{~h}$ totals) of the self-administration testing (no significant effect of Site, Type, Dose or interaction) and the doseresponse testing (no significant effect of Cocaine Dose, Agonist Dose or interaction). There were no significant effects of dopamine agonists on inactive lever presses under any condition.

\section{Discussion}

Together with our previous findings (Suto et al., 2009), the present results suggest that the satiating effects of cocaine involve the ability of cocaine to elevate extracellular dopamine in only a portion of the mesocorticolimbic dopamine terminal fields; blockade (Suto et al., 2009) and activation (present study) of dopamine receptors in NAS core but not shell shortened and prolonged, respectively, the time between earned injections. In well trained animals, the interval between self-administered injections is inversely related to injection dose and appears to reflect a period of intoxication when additional drug would not be additionally rewarding (Dougherty and Pickens, 1974; Yokel and Pickens, 1974; Gerber and Wise, 1989; Wise et al., 1995; Tsibulsky and Norman, 1999).

However, response-independent cocaine injections can cause pauses in food-rewarded as well as in cocaine-rewarded responding, and for this reason it is important to differentiate between two types of "direct rate-decreasing" effects of the drug (Pickens and Thompson, 1968). On the one hand, response pauses might reflect drug-induced performance deficits; the drug might incapacitate the animal or interrupt behavior because of incompatible stereotyped licking, chewing and head movements. On the other hand, the drug might cause a motivational deficit; while capable of executing the required response, the animal might, during periods of sufficient intoxication, become temporarily disinterested in the expected reward and unresponsive to the incentive-motivational cues that lead to it. In the case of intrave-

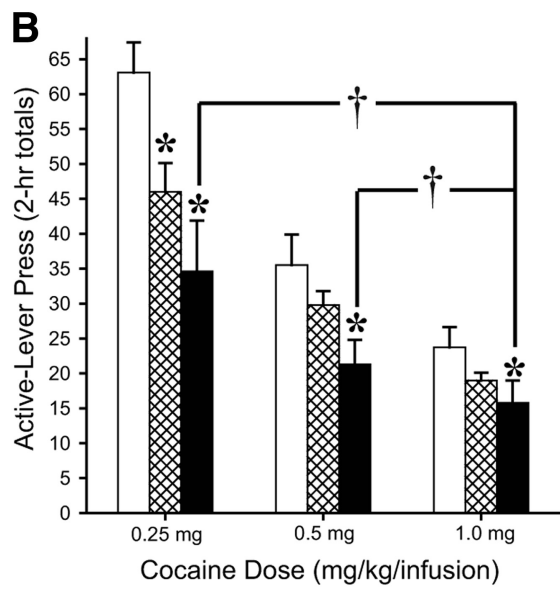

$$
\begin{aligned}
& \square \text { CORE - aCSF } \\
& \text { CORE - SKF+QUIN }(0.05+0.05 \mathrm{mM}) \\
& \text { CORE - SKF+QUIN }(0.5+0.5 \mathrm{mM})
\end{aligned}
$$

Figure 4. Effects of bilateral perfusion of D1 + D2-type (SKF + QUIN) agonists into NAS core on self-administration behavior mainained by three different unit doses of intravenous cocaine. $\boldsymbol{A}, \boldsymbol{B}$, Data are shown as the mean (+SEM) total numbers of cocaine selfinjections $(\boldsymbol{A})$ and active lever presses $(\boldsymbol{B})$ during each of the three $2 \mathrm{~h}$ blocks of the maintenance phase. ${ }^{*} p$ values $<0.01-0.05$ vs

nous cocaine self-administration, two lines of evidence make it unlikely that the former, a direct rate-decreasing effect of the drug reflecting incapacitation, determines the lack of lever pressing in the inter-response interval. First, lever pressing for a non-food reward-electrical stimulation of the lateral hypothalamus-is augmented, not disrupted, by experimenter-administered cocaine in the relevant dose range (Wauquier and Niemergeers, 1974). Second, the stereotypy typically seen between self-administered injections of amphetamine - presumably involving the same mechanism as that caused by cocaine- does not impair the ability to lever-press at normal or higher rates for brain stimulation reward (Wise et al., 1977). Finally, the ability to lever-press at shorter intervals is frequently demonstrated in the first week or two of self-administration training, when post-reinforcement pauses have not yet become established and early responses are frequently observed. Thus neither psychomotor stimulant stereotypy nor any other direct ratedecreasing effect of the drugs renders stimulant-intoxicated animals incapable of lever pressing. While the label of satiety is merely descriptive, not intended as an explanation of the behavior, it is a direct rate-suppressing effect of cocaine that reflects something more than simple incapacitation.

That pharmacological manipulations of dopamine receptors in NAS core but not shell modulated these periods of drug satiety suggests that the satiating effects of cocaine are mediated by a different subset of accumbens output neurons than those that mediate the primary reinforcing properties of cocaine. While the fully formed self-administration habit comes to involve additional, more dorsal, striatal circuitry (Everitt and Robbins, 2005; Graybiel, 2008; Suto et al., 2011) the habit-forming effects of cocaine are presumed to be due to actions in the ventromedial striatal region, because rats learn to self-administer cocaine microinjections directly into NAS shell and the adjacent olfactory tubercle but not into NAS core (Carlezon and Wise, 1996b; Ikemoto, 2003).

The fact that a combination of D1-type and D2-type agonists was required to influence inter-response times implicates a mechanism involving D1 and D2 cooperativity. This notion is supported by our previous observation that perfusion of either 
D1-type or D2-type dopamine antagonist into NAS core (rather than shell) is sufficient to modulate (increase) the rate of intravenous cocaine self-administration (Suto et al., 2009). That blockade of either blocks the behavior means that participation of both is necessary. Blocking either D1 or D2 receptors disrupts most behavioral (Woolverton, 1986; Clark and White, 1987; Plaznik et al., 1989), or electrophysiological (White and Wang, 1984), effects of cocaine-including the intracranial self-administration of dopamine agonists (Ikemoto et al., 1997) —indicating that cooperativity between both D1-type and D2-type receptor activation is required for many dopamine-associated functions. This interaction may be unique to the subpopulation of medium spiny neurons coexpressing D1-like and D2-like receptors (Surmeier et al., 1993), such as those expressing the heteromer of D1 and D3 receptors (Fiorentini et al., 2010). Alternatively, it may reflect a required interaction between parallel D1-associated and D2-associated pathways, such as the "direct" and "indirect" GABAergic output pathways of the striatum (Gerfen and Surmeier, 2011).

Whatever the mechanism, the present findings illustrate the need to resolve the reward-related effects of cocaine into at least two components. On the one hand the drug appears to be reinforcing (habit-forming) because it increases dopamine levels in NAS shell or more medial olfactory tubercle and not NAS core (Carlezon et al., 1995; Ikemoto, 2003: but see Ito et al., 2004). On the other hand, the duration of cocaine satiety-corresponding intuitively to Thorndike's label of a "satisfying state of affairs" (Thorndike, 1911)—appears to be a consequence of elevated levels of extracellular dopamine (Wise et al., 1995: also see Ranaldi et al., 1999) not in the shell, but rather in the core of NAS (Suto et al., 2009; present study).

\section{References}

Berendse HW, Groenewegen HJ, Lohman AH (1992) Compartmental distribution of ventral striatal neurons projecting to the mesencephalon in the rat. J Neurosci 12:2079-2103.

Bozarth MA, Wise RA (1985) Toxicity associated with long-term intravenous heroin and cocaine self-administration in the rat. J Am Med Assoc 254:81-83.

Carboni E, Tanda GL, Frau R, Di Chiara G (1990) Blockade of the noradrenaline carrier increases extracellular dopamine concentrations in the prefrontal cortex: evidence that dopamine is taken up in vivo by noradrenergic terminals. J Neurochem 55:1067-1070.

Carlezon WA Jr, Wise RA (1996a) Microinjections of phencyclidine (PCP) and related drugs into nucleus accumbens shell potentiate medial forebrain bundle brain stimulation reward. Psychopharmacology (Berl) 128:413-420.

Carlezon WA Jr, Wise RA (1996b) Rewarding actions of phencyclidine and related drugs in nucleus accumbens shell and frontal cortex. J Neurosci 16:3112-3122.

Carlezon WA Jr, Devine DP, Wise RA (1995) Habit-forming actions of nomifensine in nucleus accumbens. Psychopharmacology (Berl) 122:194-197.

Clark D, White FJ (1987) Review: D1 dopamine receptor-the search for a function: a critical evaluation of the D1/D2 dopamine receptor classification and its function implications. Synapse 1:347-388.

De Wit H, Wise RA (1977) Blockade of cocaine reinforcement in rats with the dopamine receptor blocker pimozide, but not with the noradrenergic blockers phentolamine or phenoxybenzamine. Can J Psychol 31:195-203.

Dougherty JD, Pickens R (1974) Effects of phenobarbital and SKF 525A on cocaine self-administration in rats. Drug Addiction 3:135-143.

Ettenberg A, Pettit HO, Bloom FE, Koob GF (1982) Heroin and cocaine intravenous self-administration in rats: mediation by separate neural systems. Psychopharmacology 78:204-209.

Everitt BJ, Robbins TW (2005) Neural systems of reinforcement for drug addiction: from actions to habits to compulsion. Nat Neurosci 8:1481-1489.

Fiorentini C, Busi C, Spano P, Missale C (2010) Dimerization of dopamine
D1 and D3 receptors in the regulation of striatal function. Curr Opin Pharmacol 10:87-92.

Gerber GJ, Wise RA (1989) Pharmacological regulation of intravenous cocaine and heroin self-administration in rats: a variable dose paradigm. Pharmacol Biochem Behav 32:527-531.

Gerfen CR, Surmeier DJ (2011) Modulation of striatal projection systems by dopamine. Annu Rev Neurosci 34:441-466.

Graybiel AM (2008) Habits, rituals, and the evaluative brain. Annu Rev Neurosci 31:359-387.

Heikkila RE, Orlansky H, Cohen G (1975) Studies on the distinction between uptake inhibition and release of $\left({ }^{3} \mathrm{H}\right)$ dopamine in rat brain tissue slices. Biochem Pharmacol 24:847-852.

Ikemoto S (2003) Involvement of the olfactory tubercle in cocaine reward: intracranial self-administration studies. J Neurosci 23:9305-9511.

Ikemoto S, Glazier BS, Murphy JM, McBride WJ (1997) Role of dopamine $\mathrm{D}_{1}$ and $\mathrm{D}_{2}$ receptors in the nucleus accumbens in mediating reward. J Neurosci 17:8580-8587.

Ito R, Robbins TW, Everitt BJ (2004) Differential control over cocaineseeking behavior by nucleus accumbens core and shell. Nat Neurosci 7:389-397.

Johanson CE, Balster RL, Bonese K (1976) Self-administration of psychomotor stimulant drugs: the effects of unlimited access. Pharmacol Biochem Behav 4:45-51.

Lecca D, Cacciapaglia F, Valentini V, Acquas E, Di Chiara G (2007) Differential neurochemical and behavioral adaptation to cocaine after response contingent and noncontingent exposure in the rat. Psychopharmacology (Berl) 191:653-667.

Lyness WH, Friedle NM, Moore KE (1979) Destruction of dopaminergic nerve terminals in nucleus accumbens: effect on $d$-amphetamine selfadministration. Pharmacol Biochem Behav 11:553-556.

Morón JA, Brockington A, Wise RA, Rocha BA, Hope BT (2002) Dopamine uptake through the norepinephrine transporter in brain regions with low levels of the dopamine transporter: evidence from knock-out mouse lines. J Neurosci 22:389-395.

Norman AB, Tsibulsky VL (2001) Satiety threshold regulates maintained self-administration: comment on Lynch and Carroll (2001). Exp Clin Psychopharmacol 9:151-154; discussion 160-162.

Paxinos G, Watson C (1998) The rat brain in stereotaxic coordinates, Ed 4. San Diego: Academic.

Pickens R, Thompson T (1968) Cocaine-reinforced behavior in rats: Effects of reinforcement magnitude and fixed-ratio size. J Pharmacol Exp Ther 161:122-129.

Plaznik A, Stefanski R, Kostowski W (1989) Interaction between accumbens D1 and D2 receptors regulating rat locomotor activity. Psychopharmacology 99:558-562.

Ranaldi R, Pocock D, Zereik R, Wise RA (1999) Dopamine fluctuations in the nucleus accumbens during maintenance, extinction, and reinstatement of intravenous D-amphetamine self-administration. J Neurosci 19:4102-4109.

Risner M, Jones BE (1976) Role of noradrenergic and dopaminergic processes in amphetamine self-administration. Pharmacol Biochem Behav 5:477-482.

Risner ME, Jones BE (1980) Intravenous self-administration of cocaine and norcocaine by dogs. Psychopharmacology 71:83-89.

Roberts DC, Corcoran ME, Fibiger HC (1977) On the role of ascending catecholaminergic systems in intravenous self-administration of cocaine. Pharmacol Biochem Behav 6:615-620.

Surmeier DJ, Reiner A, Levine MS, Ariano MA (1993) Are neostriatal dopamine receptors localized? Trends Neurosci 16:299-305.

Suto N, Ecke LE, Wise RA (2009) Control of within-binge cocaine-seeking by dopamine and glutamate in the core of nucleus accumbens. Psychopharmacology (Berl) 205:431-439.

Suto N, Ecke LE, You ZB, Wise RA (2010) Extracellular fluctuations of dopamine and glutamate in the nucleus accumbens core and shell associated with lever-pressing during cocaine self-administration, extinction, and yoked cocaine administration. Psychopharmacology (Berl) 211:267-275.

Suto N, Wise RA, Vezina P (2011) Dorsal as well as ventral striatal lesions affect levels of intravenous cocaine and morphine self-administration in rats. Neurosci Lett 493:29-32.

Thomsen M, Hall FS, Uhl GR, Caine SB (2009) Dramatically decreased cocaine self-administration in dopamine but not serotonin transporter knock-out mice. J Neurosci 29:1087-1092. 
Thorndike EL (1911) Animal intelligence. New York: Macmillan.

Tsibulsky VL, Norman AB (1999) Satiety threshold: a quantitative model of maintained cocaine self-administration. Brain Res 839:85-93.

Voorn P, Gerfen CR, Groenewegen HJ (1989) Compartmental organization of the ventral striatum of the rat: immunohistochemical distribution of enkephalin, substance P, dopamine, and calcium-binding protein. J Comp Neurol 289:189-201.

Wauquier A, Niemergeers CJ (1974) Intracranial self-stimulation in rats as a function of various stimulus parameters. V. Influence of cocaine on medial forebrain bundle stimulation with monopolar electrodes. Psychopharmacologia (Berl) 38:201-210.

White FJ, Wang RY (1984) Pharmacological characterization of dopamine autoreceptors in the rat ventral tegmental area: microiontophoretic studies. J Pharmacol Exp Ther 231:275-280.

Wise RA, Yokel RA, Hansson PA, Gerber GJ (1977) Concurrent intracranial self-stimulation and amphetamine self-administration in rats. Pharmacol Biochem Behav 7:459-461.
Wise RA, Newton P, Leeb K, Burnette B, Pocock D, Justice JB Jr (1995) Fluctuations in nucleus accumbens dopamine concentration during intravenous cocaine self-administration in rats. Psychopharmacology 120:10-20.

Woolverton WL (1986) Effects of $\mathrm{a}_{1}$ and a $\mathrm{D}_{2}$ dopamine antagonist on the self-administration of cocaine and piribedil by rhesus monkeys. Pharmacol Biochem Behav 24:531-535.

Yokel RA, Pickens R (1974) Drug level of $d$ - and $l$-amphetamine during intravenous self-administration. Psychopharmacologia (Berl) 34:255- 264.

Yokel RA, Wise RA (1975) Increased lever pressing for amphetamine after pimozide in rats: implications for a dopamine theory of reward. Science 187:547-549.

Yokel RA, Wise RA (1976) Attenuation of intravenous amphetamine reinforcement by central dopamine blockade in rats. Psychopharmacology (Berl) 48:311-318.

Zahm DS, Heimer L (1990) Two transpallidal pathways originating in the rat nucleus accumbens. J Comp Neurol 302:437-446. 